\title{
Cylindromatosis mediates neuronal cell death in vitro and in vivo
}

\author{
Goutham K. Ganjam ${ }^{1}$ • Nicole Angela Terpolilli ${ }^{2}$ Sebastian Diemert ${ }^{1}$ - Ina Eisenbach ${ }^{1}$ Lena Hoffmann ${ }^{1}$. \\ Christina Reuther ${ }^{1} \cdot$ Christiane Herden $^{3} \cdot$ Joachim Roth $^{4} \cdot$ Nikolaus Plesnila $\mathbb{( D}^{2} \cdot$ Carsten Culmsee $^{1}$
}

Received: 9 March 2017 / Revised: 18 September 2017 / Accepted: 13 November 2017 / Published online: 19 January 2018

(c) The Author(s) 2018. This article is published with open access

\begin{abstract}
The tumor-suppressor cylindromatosis (CYLD) is a deubiquitinating enzyme and key regulator of cell proliferation and inflammation. A genome-wide siRNA screen linked CYLD to receptor interacting protein-1 (RIP1) kinase-mediated necroptosis; however, the exact mechanisms of CYLD-mediated cell death remain unknown. Therefore, we investigated the precise role of CYLD in models of neuronal cell death in vitro and evaluated whether CYLD deletion affects brain injury in vivo. In vitro, downregulation of CYLD increased RIP1 ubiquitination, prevented RIP1/RIP3 complex formation, and protected neuronal cells from oxidative death. Similar protective effects were achieved by siRNA silencing of RIP1 or RIP3 or by pharmacological inhibition of RIP1 with necrostatin-1. In vivo, CYLD knockout mice were protected from traumainduced brain damage compared to wild-type littermate controls. These findings unravel the mechanisms of CYLD-mediated cell death signaling in damaged neurons in vitro and suggest a cell death-mediating role of CYLD in vivo.
\end{abstract}

\section{Introduction}

Necroptosis is a form of programmed cell death induced by the activation of death receptors such as tumor necrosis factor receptor (TNFR) or Fas and terminated through activation of receptor-interacting kinase protein-1 (RIP1), receptor-interacting kinase-3 (RIP3), and mixed lineage

Edited by N. Chandel

GK Ganjam, NA Terpolilli and S Diemert contributed equally to this work.

Electronic supplementary material The online version of this article (https://doi.org/10.1038/s41418-017-0046-7) contains supplementary material, which is available to authorized users.

Carsten Culmsee

culmsee@uni-marburg.de

1 Institute for Pharmacology and Clinical Pharmacy, BiochemicalPharmacological Center Marburg, Marburg Center for Mind, Brain and Behavior - MCMBB, University of Marburg,

Marburg, Germany

2 Institute for Stroke and Dementia Research, University of Munich Medical Center, Munich, Germany

3 Institute for Veterinarian Pathology, University of Gießen, Gießen, Germany

4 Institute for Veterinarian Physiology, University of Gießen, Gießen, Germany kinase domain-like protein (MLKL) and without the involvement of executor caspases [1]. Downstream of death receptor stimulation, the RIP homotypic interaction motif domains RIP1 and RIP3 forms RIP1-RIP3 necrosome complex [2, 3]. Activated RIP3 phosphorylates MLKL to self oligomerise and to execute necrosis [4]. However, recent observations identified alternative modes of RIP3/MLKL activation independent of RIP1 [5, 6]. Inhibition of RIP1 kinase by necrostatin-1, prevents the formation of the detrimental RIP1/RIP3 complex and necroptosis in different cell types, including neurons [7, 8]. Additional components of the necrosome may include Fas-associated protein with death domain, tumor necrosis factor receptor associated death domain (TRADD), and caspase-8 [9]. Whether all of these components are essential for programmed necrosis has not been unequivocally defined [10]. Additional triggers of necroptosis may mediate regulated necrosis independently of death receptor stimulation.

The deubiquitinating enzyme CYLD was originally identified in cylindromatosis [11], a rare inherited condition of benign skin tumors caused by CYLD mutations lacking a functional catalytic domain [12]. CYLD was described as a negative modulator of nuclear factor (NF)$\kappa \mathrm{B}$ signaling [13], TNFR-associated factor 2, NF- $\kappa \mathrm{B}$ essential modulator and RIP1. A role for CYLD has been suggested in cellular processes including proliferation and inflammation, and a genome-wide small 
interfering RNA (siRNA) screen linked CYLD to necroptosis [14]. For example, cellular inhibition of apoptosis proteins 1 and 2 (cIAP1 and cIAP2, respectively) prevented cell death by enhancing RIP1 ubiquitination, thereby antagonizing the effect of CYLD in pathways of necroptosis [3, 15-17]. Further, caspase-8mediated CYLD processing was revealed as a master switch between RIP1-dependent programmed necrosis and apoptosis downstream of death receptor activation [18].

Although pathways of RIP1-dependent necroptosis have been linked to brain injury, the role of CYLD in paradigms of neuronal cell death is unknown. Therefore, we sought to elucidate a potential role of CYLD in caspase-independent cell death pathways that were triggered by oxidative stress in neuronal cells in vitro. For this purpose, we chose a model of glutamate-induced oxidative cell death in HT-22 cells. In these immortalized hippocampal neurons, millimolar glutamate concentrations block the glutamatecystine $\left(\mathrm{Xc}^{-}\right)$transporter thereby depleting the intracellular glutathione [19]. The resulting increase in oxidative stress triggers caspase-independent mitochondrial damage, apoptosis-inducing factor (AIF) release to the nucleus and death in the absence of a death receptor stimulus [20-22].

So far, the role of CYLD in the regulation of cell death has only been investigated in cultured cell lines in vitro. Whether CYLD also plays a role in neural cell death in vivo, in paradigms relevant for human disease, has not yet been reported. After acute brain injury following ischemia or brain trauma, neurons largely die via caspaseindependent mechanisms of cell death that do not require death receptor activation but instead translocation of mitochondrial AIF to the nucleus [21, 23]. Additionally, traumatic brain damage (traumatic brain injury (TBI))-induced secondary brain damage involves acute glutamate release, loss of intracellular $\mathrm{Ca}^{2+}$ homeostasis, and oxidative cell death [24]. In the present study, we therefore investigated whether CYLD deletion exerted protective effects in a mouse model of brain trauma.

\section{Results}

\section{CYLD siRNA prevents glutamate toxicity}

To investigate the role of CYLD in neuronal HT-22 cells, we used two different CYLD siRNA sequences that depleted CYLD mRNA and protein levels (Fig. 1a, b; Supplementary Fig. S1a). Glutamate-induced morphological changes in the HT-22 cells were substantially mitigated in CYLD-depleted cells (Fig. 1c). The 3-(4,5-dimethylthiazol-2-yl)-2,5-diphenyltetrazolium bromide (MTT) assay revealed a significant degree of protection exerted by both CYLD siRNA sequences in comparison to their respective controls (Fig. 1d; Supplementary Fig. S1b), and fluorescence-activated cell sorter (FACS) analysis of AnnexinV/propidium iodide (PI)-stained cells confirmed that CYLD depletion prevented oxidative cell death (Fig. 1e). Real-time impedance measurements using the xCELLigence system showed a decrease in impedance for HT-22 cells treated with glutamate, while CYLD siRNA prevented this drop of impedance (Fig. 1f). Furthermore, CYLD depletion significantly attenuated lipid peroxidation compared to glutamate controls (Supplementary Fig. S3d).

\section{Neither glutamate nor CYLD siRNA alters NF-KB activity}

Stimulation of the NF- $\kappa \mathrm{B}$ pathway was associated with neuroprotection, although some groups claimed that NF- $\mathrm{KB}$ aggravates neural cell death due to its pro-inflammatory function $[25,26]$. Previously, lack of CYLD and the resulting increased cellular proliferation and survival was linked to an increase in NF- $\mathrm{KB}$ activity, e.g., in keratinocytes $[27,28]$. We studied NF- $\kappa B$ activity by luciferase reporter assay under basal conditions and upon CYLD depletion in the HT-22 cells, in response to either glutamate or TNF- $\alpha$. We found that CYLD depletion did not enhance NF-KB reporter activity at basal conditions or after glutamate treatment at different time points but by TNF- $\alpha$ (100 ng/ml) (Fig. 2a, b; Supplementary Fig. S3a). CYLD siRNA did not further enhance the TNF- $\alpha$-induced NF- $\mathrm{KB}$ activity, suggesting that CYLD depletion was not linked to a protective regulation of NF-KB activity in these cells (Fig. 2b).

Western blot analysis showed altered phosphorylation of inhibitor of $\kappa \mathrm{B}-\alpha(\mathrm{I} \kappa \mathrm{B}-\alpha)$ only in TNF- $\alpha$ but not after glutamate treatment and this was unaltered by CYLD siRNA (Fig. 2c). Additionally, TNF- $\alpha$ did not enhance the glutamate toxicity but rather mediated a protective effect, suggesting that TNF- $\alpha$ did not contribute to glutamate toxicity (Fig. 2d). This conclusion was further supported by TNF- $\alpha$ enzymelinked immunosorbent assay measurements of the supernatant medium of controls and after glutamate treatment for 6 and $18 \mathrm{~h}$ [29]. In these conditions, TNF- $\alpha$ was either not detectable or detected at very low levels of, e.g., $9.67 \pm 2.08$ $\mathrm{pg} / \mathrm{ml}$ in controls and $8.33 \pm 1.53 \mathrm{pg} / \mathrm{ml}$ after glutamate exposure for $18 \mathrm{~h}$. The missing role for TNF- $\alpha$ in supporting glutamate-induced cell death was confirmed using TNF- $\alpha$ antagonist infliximab $(1 \mu \mathrm{g} / \mathrm{ml})$, which prevented only necrosis induced by a cocktail of TNF- $\alpha(100 \mathrm{ng} / \mathrm{ml})$, SMAC mimetics (SM-160 $100 \mathrm{nM}$ ), and Caspase inhibitor (QVD 10 $\mu \mathrm{M})$ but not glutamate-induced oxytosis (Supplementary Fig. S1c). The necrosis-inducing cocktail instigated the 
a)

b)
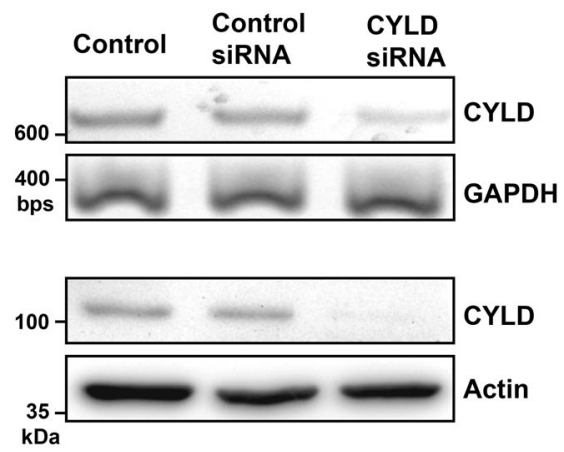

d)
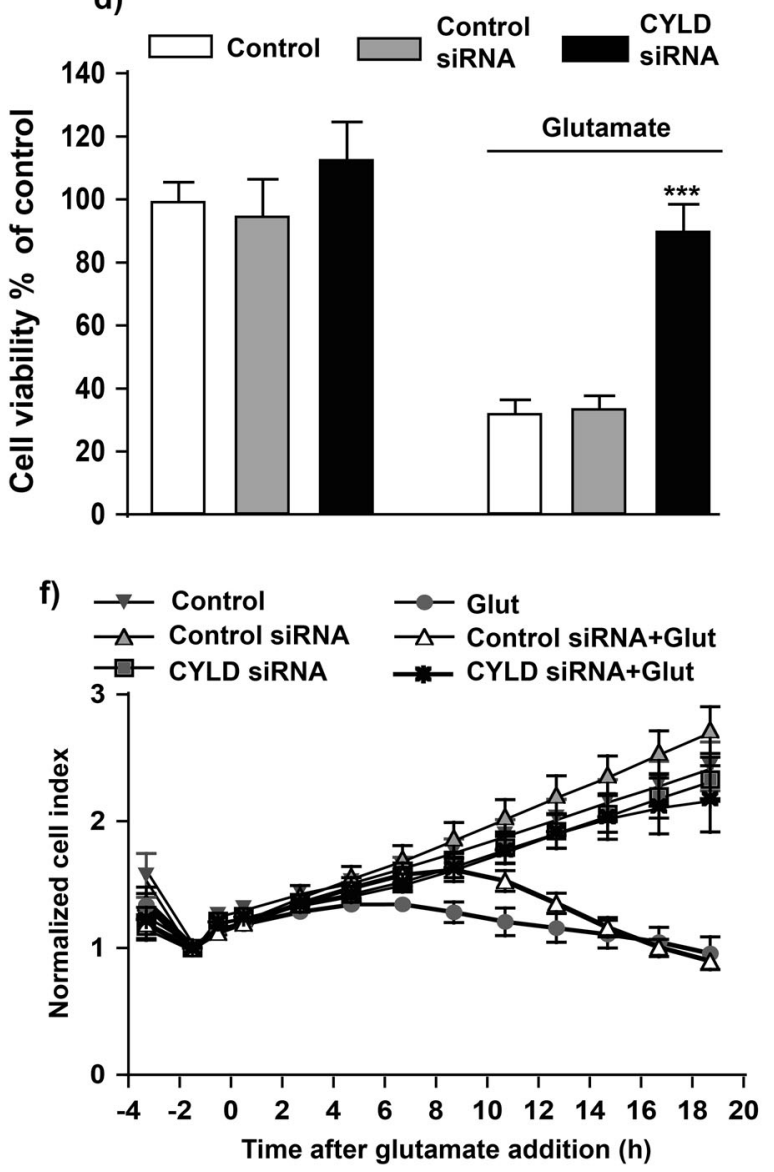

Fig. 1 CYLD siRNA attenuates glutamate toxicity in HT-22 cells. HT22 cells were transfected with CYLD siRNA for $48 \mathrm{~h}$ and a, b knockdown of CYLD mRNA and protein was confirmed by RT-PCR and western blot analysis, respectively. c Glutamate-induced cell death in HT-22 cells is accompanied by pronounced morphological changes that were prevented by CYLD siRNA. d Cell viability was assessed by MTT assay $10 \mathrm{~h}$ after addition of glutamate $5 \mathrm{mM}$. Mean values and S. D. of $n=8$ experiments per group are shown. $* * * p<0.001$, compared to glutamate-treated control (ANOVA Scheffe's). e Cell death was

RIP1/RIP3 complex formation as observed earlier [30], and the subsequent cell death was abolished by RIP1 inhibitor, necrostatin-1 (30 $\mu \mathrm{M})$ (Supplementary Fig. S1d, e). c)

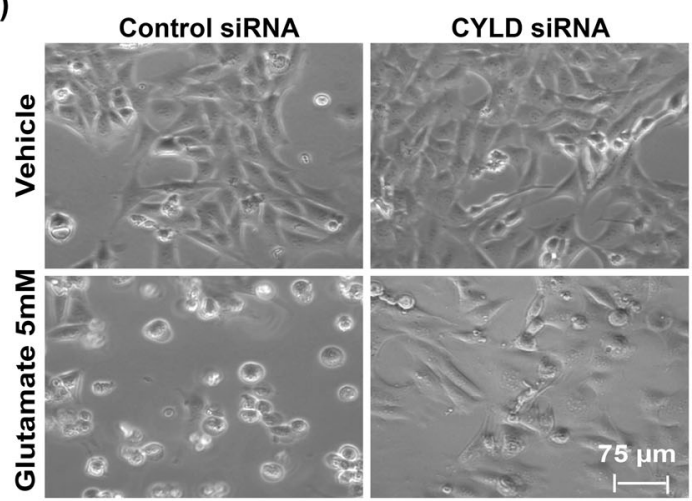

e)

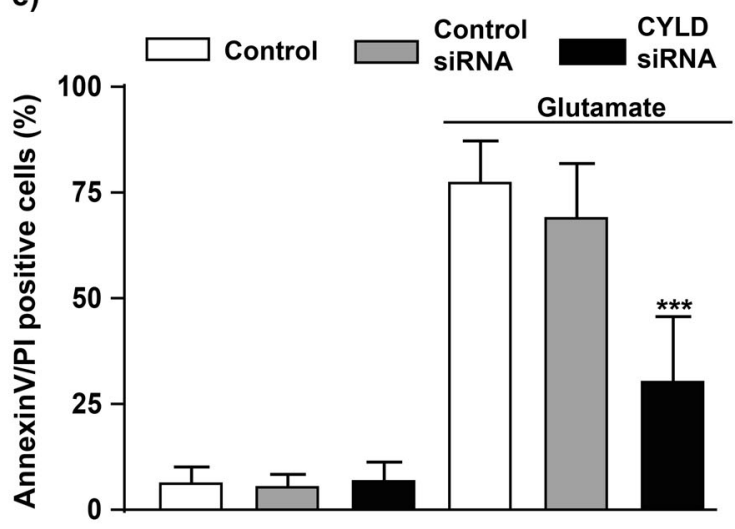

quantified by FACS analysis of Annexin V/propidium iodide-stained cells. CYLD siRNA treatment exerts a significant neuroprotective effect. Percentage of gated cells is indicated in the respective quadrants ( $n=4$ per group, 10,000 cells/sample); ${ }^{* * *} p<0.001$ compared to glutamate-treated control (ANOVA, Scheffe's). $\mathbf{f}$ Cellular impedance of HT-22 cells dropped in response to glutamate but was preserved to control levels in CYLD siRNA-treated cells. Cell index was normalized to the time point of glutamate addition. Mean values and S.D. of $n=6$ experiments per group are shown

Overall, these data suggested that TNF- $\alpha$ did not contribute to mechanisms of cell death in this model of oxidative stress. 
a)

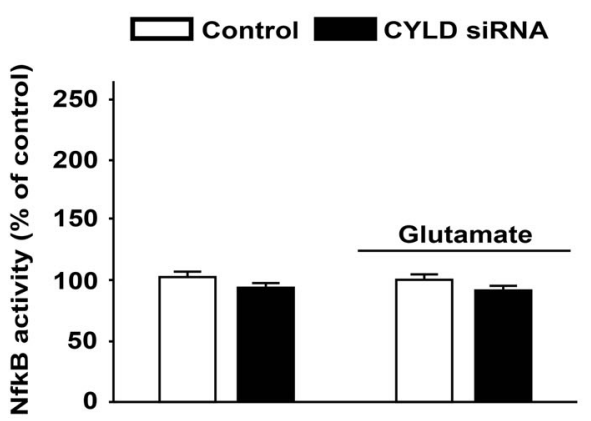

c)

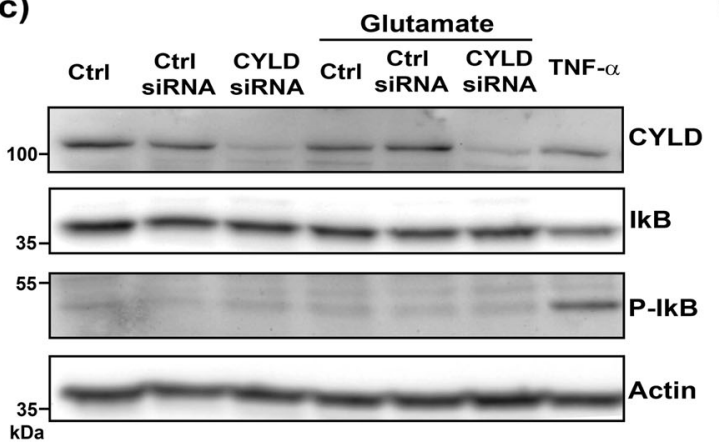

b)

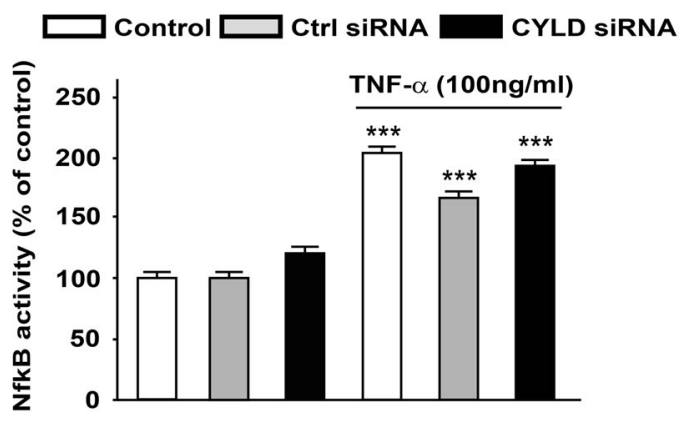

d)

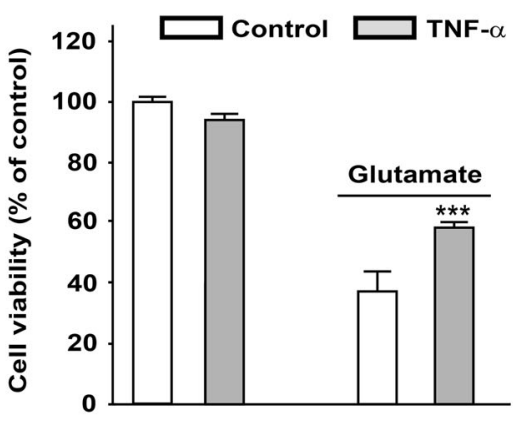

Fig. 2 Silencing CYLD did not abolish the NF-кB pathway. a HT-22 cells were transfected with control or CYLD siRNA and a luciferasedriven NF- $\mathrm{KB}$ reporter plasmid. HT-22 cells were treated with glutamate $(5 \mathrm{mM}, 8 \mathrm{~h})$ as indicated. Luminometric detection revealed a similar NF- $\mathrm{KB}$ activity in CYLD-depleted cells as compared to controls. Mean values and S.D. of $n=6$ experiments per group are shown. b HT-22 cells were transfected with control or CYLD siRNA and NF$\kappa B$ reporter plasmid for $24 \mathrm{~h}$, and the cells were treated with TNF- $\alpha$ $(100 \mathrm{ng} / \mathrm{ml}, 8 \mathrm{~h})$ as indicated. Mean values and S.D. of $n=4$

\section{Glutamate toxicity is associated with RIP1/RIP3 complex formation}

CYLD disassembles ubiquitin from lysin-63 (K63) of its target like RIP1 [31], but a role of CYLD-mediated effects on RIP1-K63 de-ubiquitination in glutamate-induced oxytosis is unknown. Hence, cells depleted of CYLD were subjected to glutamate and analyzed for RIP1-K63 ubiquitination levels by the immunoprecipitation of RIP1. We identified massive ubiquitination of RIP1 in CYLD-depleted cells only in conditions of glutamateinduced oxytosis compared to controls (Fig. 3a), suggesting that CYLD-mediated deubiquitination of RIP1 in oxidative stress was essential for RIP1/RIP3 complex formation.

Glutamate-induced cell death in HT-22 cells has been studied intensively in the past, with particular focus on reactive oxygen species (ROS) formation and oxidative stress-induced cell death [20-22]. The protective effects of CYLD siRNA prompted us to further investigate whether glutamate toxicity in HT-22 cells occurred via pathways of experiments per group are shown; $* * * p<0.001$, compared to untreated control (ANOVA, Scheffe's). $\mathbf{c}$ Western blot analysis of IкB and P-IкB levels in CYLD-depleted cells, treated with or without glutamate $(5 \mathrm{mM}, 8 \mathrm{~h})$. Treatment with TNF- $\alpha(100 \mathrm{ng} / \mathrm{ml}, 1 \mathrm{~h})$ was carried out as a positive control. NF- $\mathrm{\kappa B}$ remained constitutively inactive, regardless of CYLD depletion. d MTT cell viability assay showing exogenous addition of TNF- $\alpha(100 \mathrm{ng} / \mathrm{ml})$ did not enhance glutamate $5 \mathrm{mM}(10 \mathrm{~h})$ toxicity in HT-22 cells

programmed necrosis. Therefore, we checked for the formation of RIP1/RIP3 complex as an important regulator of necroptosis. Immunoprecipitation experiments revealed that oxytosis was associated with a time-dependent increase in RIP1/RIP3 interaction, peaking at $12 \mathrm{~h}$ post glutamate exposure (Fig. 3b, d). Silencing of CYLD by siRNA averted this RIP1/RIP3 complex formation in glutamate-exposed cells (Fig. 3c, e).

Our data unveil a role of RIP1/RIP3-dependent necroptosis pathways in glutamate-induced oxytosis that is similar to the induction of necroptosis via extrinsic death receptor stimulation. These results suggest that intrinsic activation of CYLD by oxidative stress is a key step in RIP1/RIP3 necrosome formation and subsequent necroptotic death pathways.

\section{Depletion of RIP1 and RIP3 but not MLKL prevents oxytosis by glutamate}

The molecular stability of RIP1 and RIP3 depends in large parts on the activity of heat shock protein 90 (HSP90). 


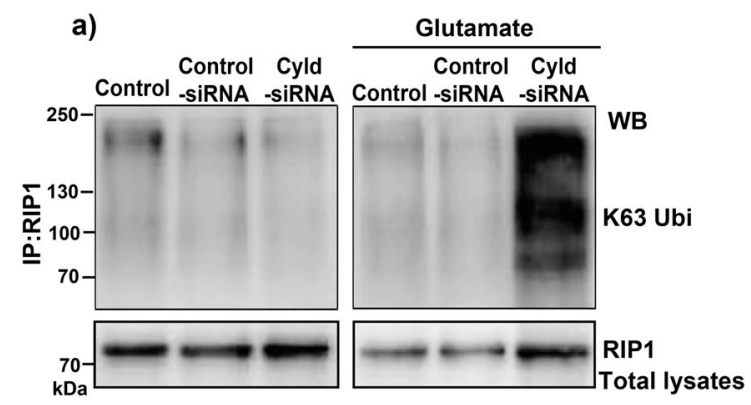

b)
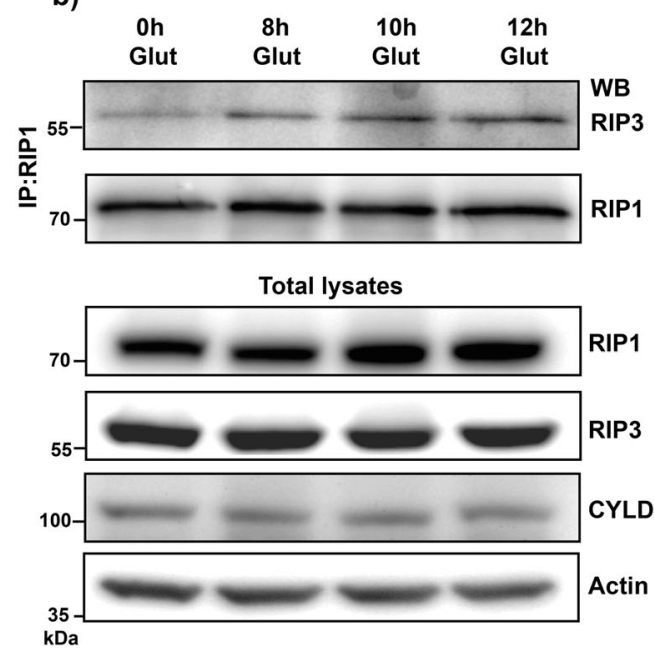

d)

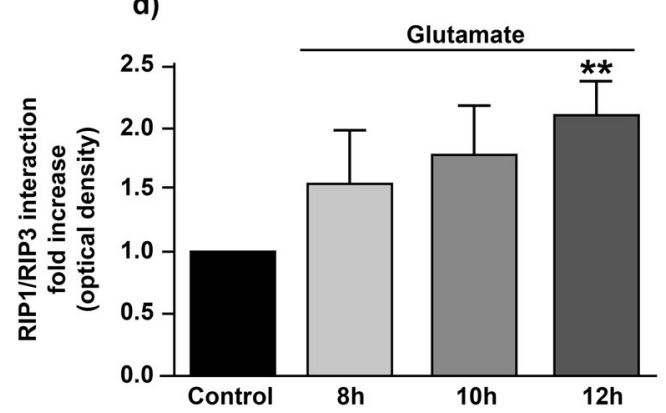

Fig. 3 CYLD regulates RIP1-RIP3 necrosome formation in response to glutamate by deubiquitination of RIP1. a HT-22 cells were depleted with CYLD siRNA ( $40 \mathrm{nM}$ ) and treated with $5 \mathrm{mM}$ glutamate for $12 \mathrm{~h}$. Immunoprecipitated RIP1 protein was analyzed for lysin 63 ubiquitination by western blot using K63-specific antibody. The same blot was used to detect RIP1 by western blot. b HT-22 cells were treated with glutamate $(5 \mathrm{mM})$ over the indicated times. Immunoprecipitation of RIP1 and subsequent analysis of co-precipitated proteins by western blot analysis showed an increased interaction with RIP3 (upper panel). Equal loading was verified by western blot analysis (lower panels). d Quantification of RIP1/RIP3 interaction, by assessing the RIP3/RIP1

Therefore, we applied the competitive HSP90 inhibitor geldanamycin to reduce RIP1 and RIP3 levels [32]. Western blot confirmed the downregulation of both RIP proteins by geldanamycin $(1 \mu \mathrm{M})$ in HT-22 cells. Importantly, this decrease in RIP1 and RIP3 proteins coincided with

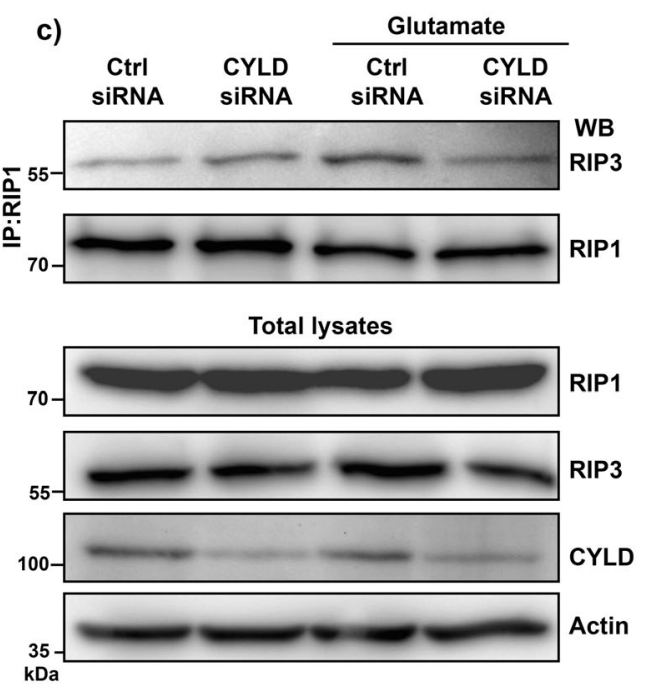

e)

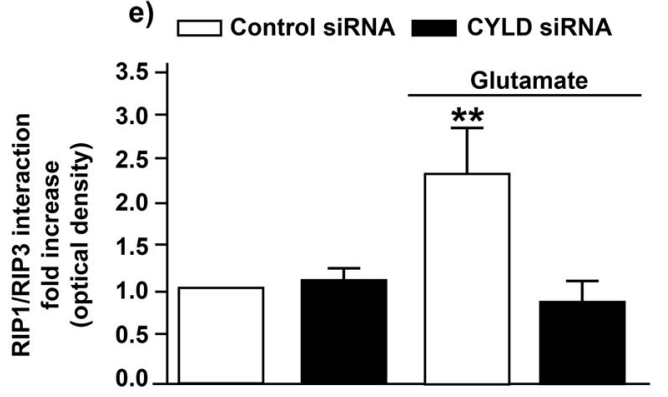

ratio, relative to control. Mean values and S.D. of $n=3$ experiments are shown; **p 0.01 compared to control (ANOVA, Scheffe's). c HT-22 cells were transfected with control and CYLD siRNA, exposed to glutamate $(5 \mathrm{mM})$, and harvested after $12 \mathrm{~h}$. RIP1 protein was immune-precipitated from whole-protein extracts and the level of co-precipitated RIP3 proteins was analyzed by western blot (upper panel). Equal loading and CYLD knockdown was verified in the whole-cell extracts. e The degree of interaction was quantified by assessing the RIP3/RIP1 ratio, relative to control. Mean values and S.D. of $n=3$ experiments are shown; $* * p<0.01$ compared to control (ANOVA Scheffe's)

significantly attenuated glutamate toxicity (Fig. 4a, b). The individual roles of RIP1 and RIP3 in the oxytosis model were investigated using the respective siRNAs. As shown in Fig. 4c, d, RIP1 siRNA significantly protected cells against glutamate toxicity. Similarly, RIP3 silencing also provided 
significant protection against glutamate-induced cell death (Fig. 4e, f), however, with lower efficacy as compared to the effects of RIP1 siRNA.
Necrostatins are widely used as inhibitors of RIP1 kinase to block necroptosis pathways. Here we confirmed a protective effect of necrostatin-1 in the model system of a)

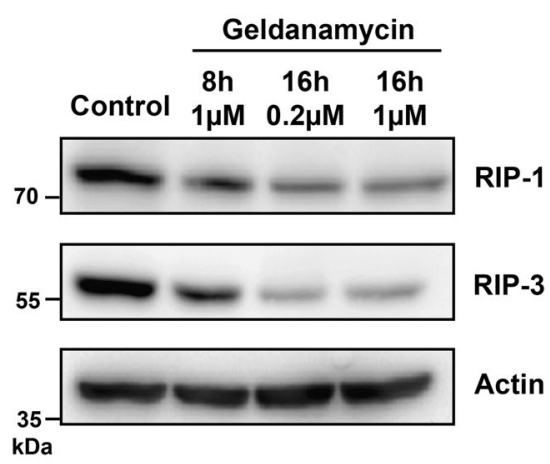

c)

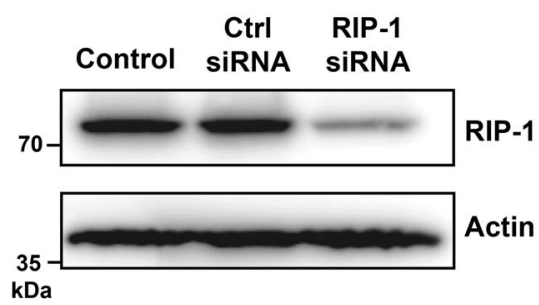

e)

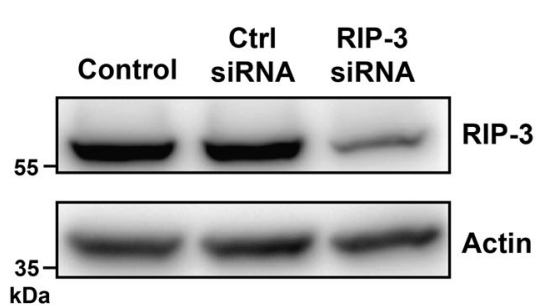

g)

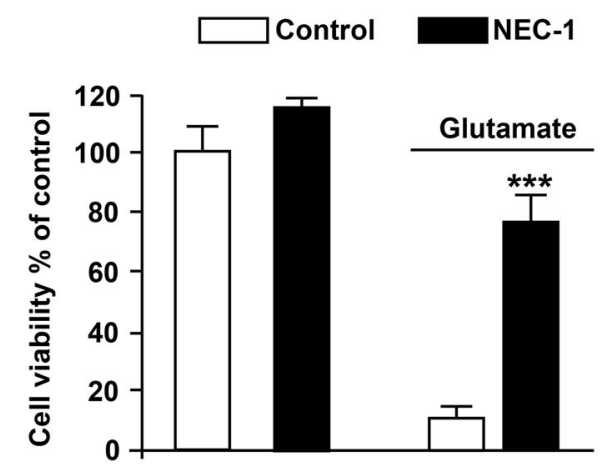

b)

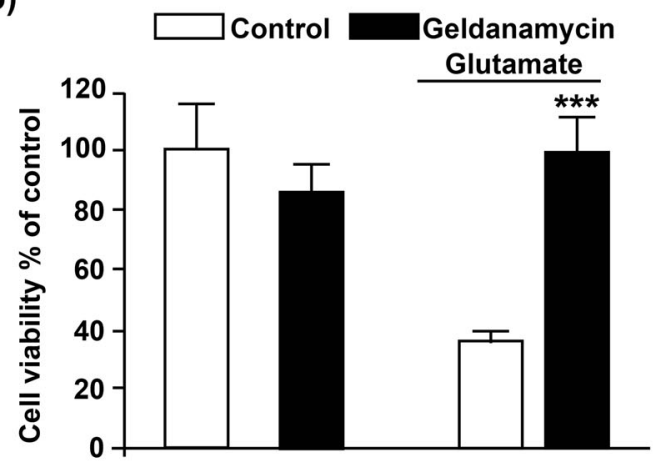

d)

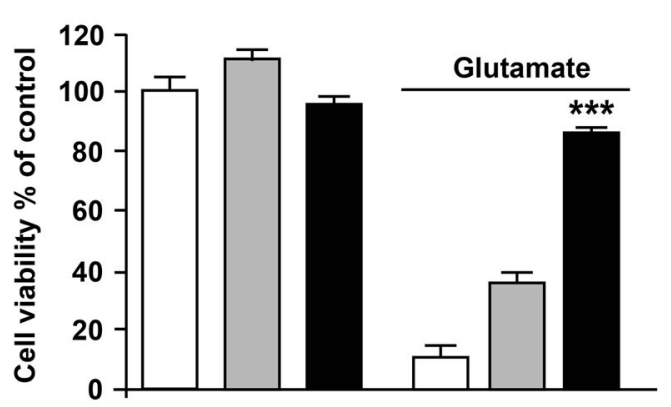

f)
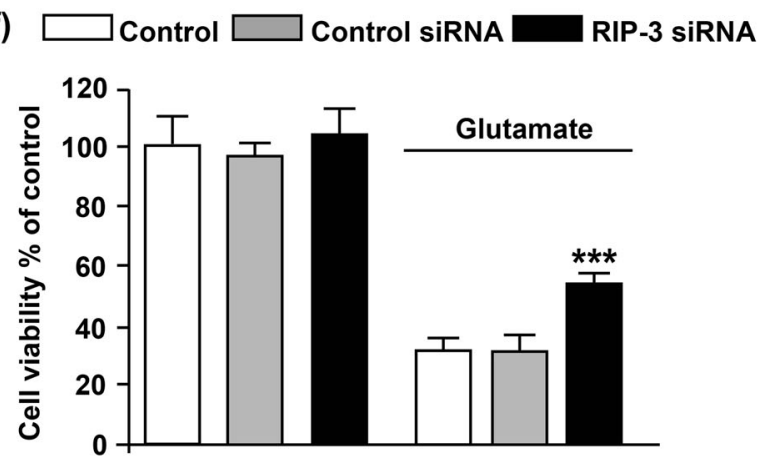

h)

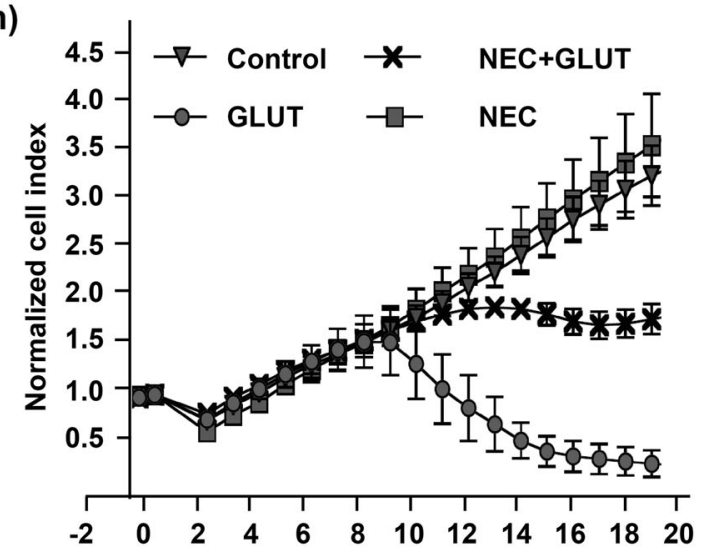


Fig. 4 Inhibiting RIP1 and RIP3 promote neuronal survival in oxidative stress model of HT-22 cells. a HT-22 cells were exposed to geldanamycin $(0.2$ and $1 \mu \mathrm{M})$ for the indicated times. Protein levels of RIP1 and RIP3 were evaluated by western blot analysis, showing a time-dependent decrease of both RIP kinase proteins. b HT-22 cells were treated with geldanamycin $(1 \mu \mathrm{M})$ and co-stimulated with glutamate $(5 \mathrm{mM})$. As assessed by the MTT assay, geldanamycin abolished glutamate toxicity. Mean values and S.D. of $n=8$ experiments per group are shown; $* * * p<0.001$ compared to control (ANOVA Scheffe's). c HT 22 cells were transfected with RIP1 siRNA (40 nM) and knockdown efficiency was evaluated by western blot. d HT-22 cells transfected with RIP1 siRNA were treated with glutamate. Cell viability as assessed by the MTT assay showed a significant protection of RIP1-depleted cells. Mean values and S.D. of $n=8$ experiments per group are shown. $* * * p<0.001$, compared to glutamate-treated control (ANOVA, Scheffe's). (e) RIP3 siRNA caused a significant reduction of RIP3 protein levels. f MTT assay analysis of RIP3 siRNA-treated cells reveals a significant protection against glutamate-dependent cell death. Mean values and S.D. of $n=8$ experiments per group are shown; $* * * p<0.001$, compared to glutamate-treated control (ANOVA, Scheffe's). $\mathbf{g}, \mathbf{h}$ HT-22 cells were treated with glutamate and necrostatin-1 $(30 \mu \mathrm{M})$ over $10 \mathrm{~h}$. Cell viability was determined by the MTT assay (g) and impedance measurement (h) showed a strong neuroprotective effect of necrostatin-1. Mean values and S.D. of $n=8$ experiments per group are shown. $* * * p<0.001$, compared to glutamate-treated control (ANOVA, Scheffe's)

oxytosis. Both the MTT assay and impedance-based detection of cell death reflected the strong and persistent protective effect of necrostatin-1 against glutamate toxicity, thus also confirming the previous results obtained by siRNA-mediated knockdown of RIP1 (Fig. 4g, h). Additionally, the RIP1-specific inhibitor Nec-1s prevented glutamate-induced oxytosis as measured by the MTT assay (Supplementary Fig. S3b) and FACS analysis of Annexin V/PI staining (Supplementary Fig. S3c). However, knockdown or pharmacological inhibition of MLKL protected only TNF-cocktail-induced cell death but not glutamateinduced oxytosis (Supplementary Fig. S4a, b). In summary, our findings strongly support the significant contribution of RIP1 and RIP3 to oxytosis downstream of CYLD activation.

\section{$\mathrm{CYLD}^{-/-}$animals were protected against TBI}

To investigate whether CYLD was relevant for neuronal cell death in vivo, we used CYLD-deficient mice and their wild-type littermates in a clinically relevant model of TBI. TBI was induced by the well-established controlled cortical impact model, i.e., by driving a piston with high velocity into the right parietal cortex. Secondary brain damage and subsequent brain edema formation were significantly reduced in $\mathrm{CYLD}^{-/-}$animals as compared to wild-type littermates (Fig. 5a, b). Further, the increase in intracranial pressure, a clinically highly relevant parameter for the management of TBI patients, was significantly reduced in $\mathrm{CYLD}^{-1-}$ mice (Fig. 5c). Importantly, neuroprotection mediated by CYLD deficiency was not transient but persisted beyond the acute phase of brain injury, i.e., 7 days after TBI (Fig. 5d).

Accordingly, CYLD mediates cell death and secondary brain damage in vitro and in vivo and may therefore represent a potential novel target for the treatment of brain injury.

\section{Discussion}

In this study, we unveil a novel role of CYLD in paradigms of neuronal cell death in vivo and in vitro. CYLD ${ }^{-/-}$animals were significantly protected from the secondary brain damage induced by TBI, demonstrating, for the first time, a major role for CYLD in neuronal death in vivo. In vitro, we further demonstrated that CYLD linked paradigms of oxidative stress and necroptosis in neuronal cells. CYLD depletion by siRNA prevented RIP1 deubiquitination, formation of the RIP1/RIP3 complex, and cell death. Our results expose CYLD as a mediator of necroptosis inducing RIP1/RIP3 complex formation in neurons in vitro and demonstrate a major role of such CYLD-mediated death pathways in acute brain injury in vivo.

The discovery of a controlled signaling network regulating programmed necrosis dispensed the view that necrotic cell death always occurs in an uncontrolled manner [14]. The exact mechanisms of programmed necrosis are unknown and only few key regulators have been identified so far [7]. The formation of RIP1/RIP3 necrosome complex is considered as a central regulating component in necroptosis [14, 33]. Previous studies revealed increased ROS formation in paradigms of RIP3-dependend necrosis induced by TNF, where ROS mediated a positive feedback loop to enhance necrosome formation [34]. A recent study showed that ROS promoted RIP1 autophosphorylation at S161, suggesting RIP1 as a ROS sensor in paradigms of TNF-induced necroptosis [35]. In support of these studies, we identified increased RIP1/RIP3 complex formation in response to glutamate-induced oxidative stress in neuronal cells. Furthermore, we demonstrated that CYLD played an important role in ROS-mediated RIP1/RIP3 complex formation and cell death, suggesting CYLD as a sensor for oxidative stress in neuronal cells. However, neither genetic nor pharmacological inhibition of MLKL prevented glutamate toxicity (Supplementary Fig. S4a, b). In contrast to classic necrosis, where MLKL activation and associated cell membrane disruption is considered as final step of cell death, in neurons, MLKL activation might be less important as compared to mitochondrial damage as it is established as the point of no return in the current model of oxidative cell death. This also applies in vivo, where mitochondrial damage and AIF release was demonstrated as a major hallmark of TBI-mediated secondary brain damage [36]. 
a)

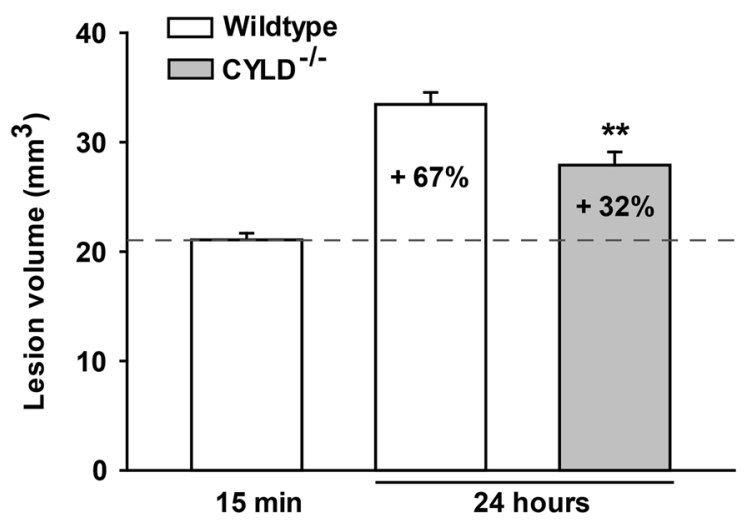

c)

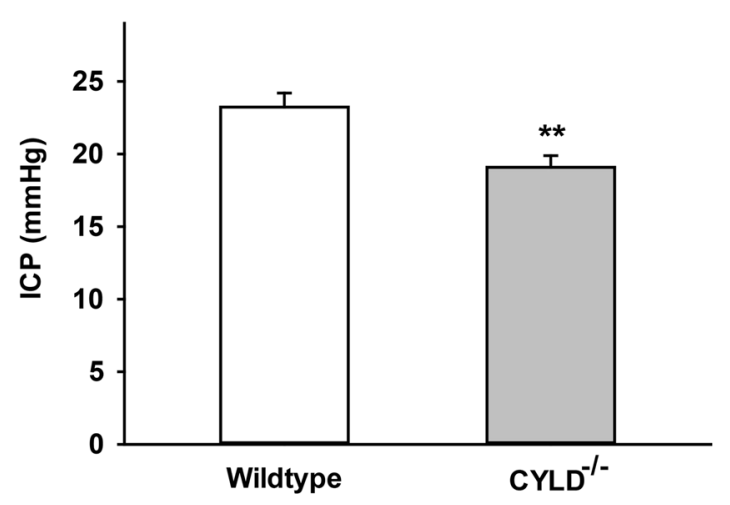

Fig. $5 \mathrm{CYLD}^{-/-}$mice are protected from posttraumatic brain damage. a Volume of injured brain tissue $15 \mathrm{~min}$ and $24 \mathrm{~h}$ after experimental traumatic brain injury (TBI) assessed by histomorphological analysis on cresyl violet-stained coronal brain sections. Lesion volume assessed $15 \mathrm{~min}$ after TBI represents the primary, untreatable injury, while the lesion volume assessed $24 \mathrm{~h}$ after TBI represents the final injury. Accordingly, the difference between the final and the primary injury represents secondary brain damage, i.e., the component of the injury which is mediated by delayed cell death signaling. In wild-type mice, secondary injury is $67 \%$ larger than the primary injury, while in CYLD-deficient mice secondary injury is almost halved $(+32 \%$; **p $<0.007$, Rank-Sum test, $n=8$ each group). b Brain edema formation in wild-type and CYLD-deficient mice assessed by measurement of brain water content. Not traumatized mice of either phenotype had a

We found that RIP1 inhibition by necrostatin-1 or necrostatin-1s prevented oxytosis in HT-22 cells (Fig. 4g, Supplementary Fig. S3b, c), and depletion of either RIP1 or RIP3 using siRNA or geldanamycin ameliorated glutamate toxicity. Importantly, depletion of CYLD resulted in increased K63 ubiquitination of RIP1 after exposure to glutamate and failed to form the RIP1/RIP3 complex. These findings indicated that CYLD regulated RIP1/ RIP3-necrosome formation in glutamate-induced oxytosis via the deubiquitination of RIP1. In line with our findings, it b)

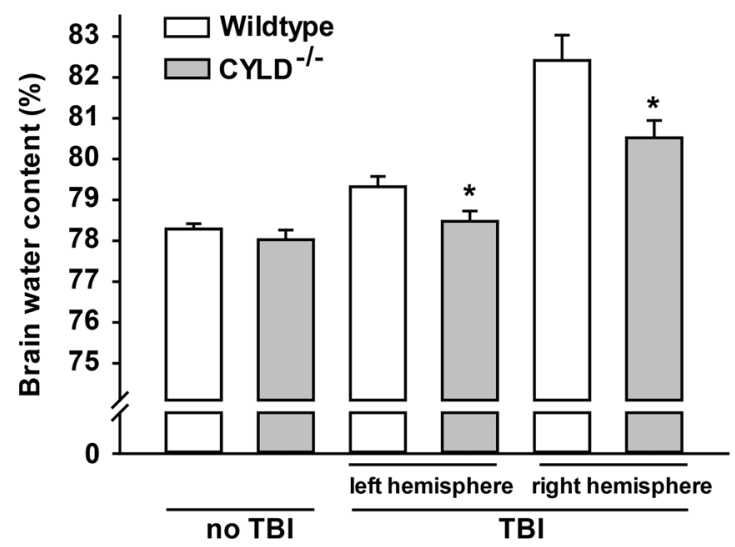

d)

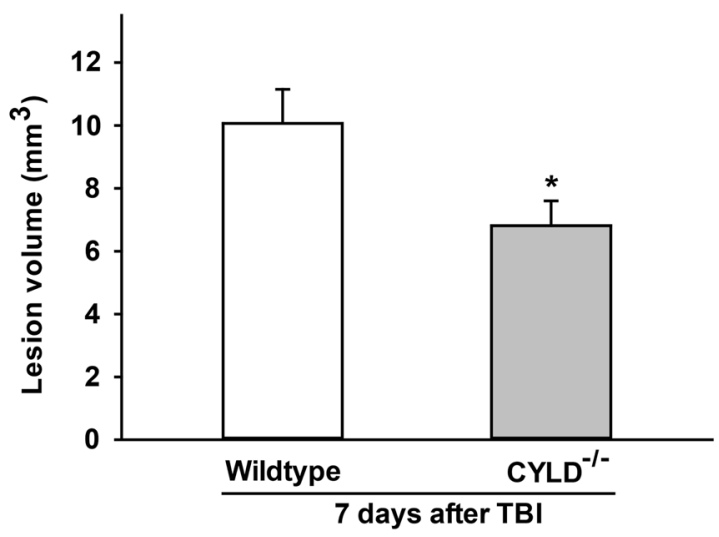

normal brain water content of approximately $78 \%$ (wild type: $78.3 \pm$ $0.4 \%, \mathrm{CYLD}^{-1-}: 78.0 \pm 0.7 \%$; n.s.). At the time point of maximal brain edema formation, i.e., $24 \mathrm{~h}$ after TBI, CYLD-deficient mice developed significantly less brain edema in both hemispheres that their wild-type littermates (not traumatized hemisphere: $78.5 \pm 0.3$ vs. 79.3 $\pm 0.3 \%, * p<0.04$; traumatized hemisphere: $80.5 \pm 0.4$ vs. $82.4 \pm$ $0.6 \%, * p<0.03$; Rank-Sum test; $n=9$ each group). c Decreased edema formation translated into significantly lower intracranial pressure in CYLD-deficient mice $(19.1 \pm 0.8 \mathrm{mmHg})$ compared to wild type $(23.2 \pm 1.0 \mathrm{~mm} \mathrm{Hg}, * * p<0.002, n=8$ each group). d Acute neuroprotection observed in CYLD-deficient mice persisted long term. Seven days after experimental TBI, lesion volume was still significantly lower in CYLD-deficient animals $\left(6.8 \pm 0.8 \mathrm{~mm}^{3}\right)$ than in wild-type littermates $\left(10.3 \pm 1.1 \mathrm{~mm}^{3},{ }^{*} p=0.03\right.$, Rank-Sum test, $n=$ 8 each)

has been shown that CYLD regulates RIP1 ubiquitination in the necrosome to facilitate RIP1 activation in TNF- $\alpha$ induced programmed necrosis [37].

Death receptors are tightly interwoven with downstream effectors, thereby, determining several different pathways of regulated cell death. For example, TNF- $\alpha$ may induce cell death through distinct death-inducing signaling complexes (DISC) [7, 9]. These DISC complexes contain the TNFR and TRADD and may promote cell death either through caspase-8 dependent apoptosis or RIP1-RIP3-dependent necroptosis. 
In our model system of oxytosis, TNF- $\alpha$ alone failed to induce necroptotic cell death as also observed in other cell systems, where TNF- $\alpha$ requires a further stimulus. When applied together with the caspase inhibitor QVD and the cIAP inhibitor and SMAC-mimetic SM-164, TNF- $\alpha$ induced necroptosis via RIP1-RIP3 necrosome formation, which was significantly inhibited by necrostatin-1, MLKL inhibitor or MLKL-siRNA (Supplementary Figs. S1d and $\mathrm{S} 4 \mathrm{a}, \mathrm{b})$. Although the molecular entities forming the necrosome are almost identical to death receptor-initiated complex II, the RIP1/RIP3 complex formed independently of death receptor stimulation in the present model system of oxytosis. Our findings are in line with recent reports, suggesting that the pathways initiating regulated necrosis may include oxidative stress attributed to superoxide and nitric oxide production [38]. According to these studies, superoxide production in the mitochondria causes NO-dependent reduction of mitochondrial complex I activity and RIP1/ RIP3-mediated necroptosis. These findings support the conclusion that RIP1/RIP3-dependent cell death can also be triggered by intracellular stimuli, as in our oxytosis model. Additionally, we now identified a major role of CYLD in mediating RIP1/RIP3-dependent necroptosis triggered by oxidative stress.

Further, an interconnection between established oxytosis model in HT-22 cells and programmed necrosis was provided by an earlier study reporting a putative role of glutathione metabolism and, namely, glutathione peroxidase 4 (Gpx4) in necroptosis [14]. As previously established, the early initiation of cell death in HT-22 cells is closely linked to a decline in glutathione levels and subsequent increases in ROS levels through enhanced activity of 12/15 lipoxygenases [20, 39]. In earlier studies using an inducible Gpx4 knockout system in fibroblasts and neurons, we and others confirmed the functional loss of $\mathrm{Gpx} 4$ as the underlying mechanism linking decreased glutathione levels and increases in lipid peroxidation [20,40]. In light of these findings, loss of Gpx4 activity after glutamate exposure of HT-22 cells likely initiates the detrimental pathways of $12 /$ 15-LOX-dependent oxidative cell death. Depletion of CYLD prevented glutamate-induced lipid peroxidation (Supplementary Fig. S3d). These results expose a key role for CYLD in oxytosis and the subsequent formation of RIP kinase complexes, thereby interconnecting apoptotic and necroptotic pathways in this model system.

Cleavage of CYLD by caspase- 8 has been identified as the key event in shifting RIP kinase-dependent necrosis to caspase-dependent apoptosis, exposing caspase 8 and CYLD as master switches between apoptosis and necrosis [18]. In the present model system of oxytosis, caspase- 8 activity remained at control levels in HT-22 cells undergoing glutamate dependent cell death, and pan-caspaseinhibitors (Supplementary Fig. S2d) or caspase-8 inhibitors did not affect glutamate [22]. These observations are consistent with previous studies demonstrating that depleted glutathione (GSH) levels due to ROS resulted in the inactivation of caspase-8, thus implicating oxidative stressinduced cell death to be caspase independent [41]. Therefore, in the present model system of oxytosis, cell death is promoted in a RIP1/RIP3-dependent manner and independently of caspase activity. The observation that neither CYLD nor RIP1 nor RIP3 were markedly degraded during cell death further supported this conclusion, suggesting that caspase- 8 activity was restrained in this model system, thereby allowing for the proposed CYLD-dependent necroptotic pathways.

Previously, CYLD was characterized as an important negative regulator of NF- $\mathrm{KB}$ signaling and functional impairment of CYLD was linked to enhanced NF- $\mathrm{KB}$ activity, tumorigenesis, and impaired immune response [28]. Notably, in our model system of neural HT-22 cells, repression of CYLD did not alter NF- $\mathrm{BB}$ activity in either control or glutamate conditions. These results propose novel CYLD-dependent death signaling pathways independent of NF- $\kappa B$ regulation. This is in contrast, for example, to the effect of CYLD depletion in human cholesteatoma epithelial cells, where increases in NF- $\mathrm{KB}$ activity were proposed as key mechanisms of enhanced cell proliferation and survival [27]. Although neuroprotection was linked to increased NF- $\kappa B$ activity [42], the observed protection against oxidative death by CYLD siRNA in the present study occurred independently of NF- $\mathrm{KB}$ activation. Recent studies demonstrated that the contribution of RIP1 to TNF$\alpha$-mediated death was not regulated by NF-kB but by an NF-kB-independent function of IKK [43, 44].

While the ubiquitinated form of RIP1 has been linked to the enhanced binding to transforming growth factor- $\beta$ activated kinase 1 and the subsequent activation of NF- $\mathrm{KB}$ survival signaling, deubiquitinated RIP1 facilitates the formation of death receptor-initiated complex II, thereby promoting cell death $[3,15,17]$. Ubiquitination of RIP1 is predominantly mediated by the ubiquitin ligases cIAP1 and cIAP2 [45]. Consequently, the depletion of cIAPs by SMAC mimetics promoted cell death by affecting RIP1 ubiquitination [15]. Similarly, SMAC mimetics sensitized cells to necroptosis in response to TNF- $\alpha[3,16]$. The deubiquitinating enzyme CYLD, in turn, cleaves off ubiquitin residues from RIP1 and loss of CYLD or caspase-8mediated CYLD processing prevents TNF- $\alpha$-induced necroptosis $[14,18,28]$. In our study, however, we did not detect any effect of SMAC mimetics on cellular viability, although cIAP levels were markedly reduced (Supplementary Fig. S2a, b). Further, depletion of cIAPs did not affect protection mediated by CYLD depletion (Supplementary Fig. S2c). This is of particular interest, since cIAPs are believed to functionally antagonize the effects of CYLD 
on RIP1 ubiquitination and an effect at this level was expected. The degree of RIP1 ubiquitination fell below the level of detection by western blot analysis, likely due to the small amount of ubiquitin bound to RIP1. However, we detected increased RIP1 ubiquitination following CYLD depletion in HT-22 cells exposed to glutamate, indicating that under oxidative stress, CYLD regulates RIP1 ubiquitination leading to RIP1/RIP3 complex formation. In contrast, cIAP depletion did not facilitate glutamate-induced CYLD and RIP kinase-dependent death signaling in HT-22 cells, though the loss of cIAP1 and cIAP2 could be compensated by other, yet unidentified E3-ligases.

In line with the detrimental role of CYLD in oxidative neuronal death in vitro, $\mathrm{CYLD}^{-1-}$ animals were significantly protected against brain damage induced by TBI. Compared to their wild-type littermates, $\mathrm{CYLD}^{-1-}$ mice showed pronounced reduction in brain edema formation and significantly reduced intracranial pressure and contusion volume. Many studies indicated acute posttraumatic release of glutamate causes excitotoxicity involving the mechanisms of oxidative stress and neuronal cell death [24]. This secondary loss of brain tissue caused by glutamate excitotoxicity is reflected in the increase in brain damage detected after $24 \mathrm{~h}$ compared to the cortical impact after $15 \mathrm{~min}$ of TBI (Fig. 5a). Earlier studies proposed a role for RIP1dependent necroptosis in rodent models of ischemic brain injury, retinal ischemia reperfusion injury, and in neonatal hypoxia/ischemia [46, 47]. Additionally, the critical downstream regulators of necroptosis RIP1, RIP3, and MLKL were recently shown to be involved in TBI-induced necrotic brain damage [48-51]. However, necrostatin-1 raised some critical discussions regarding specificity and the effective concentration for in vivo applications [52]. While a role for CYLD has been identified in an in vitro screen for regulators of necroptosis, none of the previous studies on in vivo neuronal injury identified a major role for CYLD. Further, CYLD was linked to cell proliferation, survival, inflammation, and immune responses, which may all be activated after brain injury and contribute to neuronal damage. Using $\mathrm{CYLD}^{-1-}$ mice, we now revealed the impact of this regulator of necroptosis in the model of TBI. Previous studies using the RIP1 inhibitor necrostatin-1 revealed pronounced protective effects in models of TBI, supporting a role for necroptosis in traumatic neuronal injury in vivo $[50,51]$.

Overall, our findings describe an important role for CYLD in neuronal cell death. In HT-22 cells, CYLD mediates programmed necrosis by RIP1/RIP3 complex formation independently of death receptor signaling. Showing the significant protective effect of CYLD depletion in a model of TBI in mice, we identify this novel pathway of oxidative necroptosis, and CYLD in particular, as a key regulator of brain injury in vivo.

\section{Materials and methods}

\section{Cell culture and viability assays}

HT-22 cells were cultured in Dulbecco's Modified Eagle Medium (DMEM, Invitrogen, Karlsruhe, Germany) supplemented with $10 \%$ heat-inactivated fetal calf serum, $100 \mathrm{U} / \mathrm{ml}$ penicillin, $100 \mu \mathrm{g} / \mathrm{ml}$ streptomycin, and $2 \mathrm{mM}$ glutamine. Glutamate toxicity was assessed at a final concentration of $2-4 \mathrm{mM}$ glutamate, and cell viability was evaluated $12 \mathrm{~h}$ later. Quantification of cell viability in HT22 cells was performed in 96-well plates by MTT reduction at $0.25 \mathrm{mg} / \mathrm{ml}$ for $1 \mathrm{~h}$. The reaction was terminated by removing the medium and freezing the plate at $-80^{\circ} \mathrm{C}$ for at least $1 \mathrm{~h}$. Absorbance was then determined after solving MTT dye in dimethyl sulfoxide (DMSO) at $570 \mathrm{~nm}$ vs. 630 nm (FluoStar, BMG Labtech, Offenburg, Germany). Necrostatin-1, zVAD-fmk (both by Enzo Life Sciences, Farmingdale, NY, USA), or geldanamycin (Biozol, Eching, Germany) were added to the medium at a final concentration of 25,50 or $1 \mu \mathrm{M}$, respectively. Controls always received the vehicle (DMSO) at the same concentration as the groups receiving the pharmacological compounds.

Continuous real-time detection of cellular viability was performed by measurement of cellular impedance using the xCELLigence system (Roche, Penzberg, Germany) [53]. For Annexin-V/PI staining, HT-22 cells were cultured in 24-well plates and exposed to glutamate. The cells were harvested using Trypsin/EDTA, washed once in phosphatebuffered saline, and resuspended in binding buffer (PromoKine, Heidelberg, Germany). PI and AnnexinV-fluorescein isothiocyanate (PromoKine Annexin V-FITC Detection Kit) were added ( $1 \mu \mathrm{l}$ per $100 \mu \mathrm{l}$ buffer) and incubated for $5 \mathrm{~min}$ at room temperature. Apoptotic and necrotic cells were detected using a FACScan (Becton Dickinson, San Jose, CA, USA). Annexin-V and PI fluorescence was exited at a wavelength of $488 \mathrm{~nm}$ and emission was detected at $530 \pm 40 \mathrm{~nm}$ and at $680 \pm 30 \mathrm{~nm}$, respectively. For each sample, 10,000 cells were analyzed.

\section{Plasmid and siRNA transfection}

Transfection of siRNA was conducted using RNAiMax (Invitrogen) according to the manufacturer's instructions. In brief, 5 pmol of siRNA duplexes were diluted in $100 \mu \mathrm{l}$ Opti-MEM medium (Invitrogen), to which $1 \mu \mathrm{l}$ of RNAiMax was added. The mixture was immediately transferred to the culture plate. Following an incubation period of 20 min, HT-22 cells were seeded at a density of 33,000 cells/ well in a 24-well format in $500 \mu$ DMEM medium without antibiotics. Single sequence-specific siRNA duplexes were used for murine CYLD (5'-UGAAAUGACUGAGC 
GAUAA-3) and RIP1 (5'-GAAUGAGGCUUACAA CAGA-3'), and a predesigned non-targeting siRNA was used as a negative control (all siRNAs from Eurofins MWG Operon, Ebersberg, Germany). The validated smartpool ONTARGETplus siRNA for RIP3 5'-UCAAGAUC GUGAACUCGAA-3'; 5'-CAAGUUCGGCCAAGUAUG A-3'; 5'-GGUAAAGCAUUAUCUGUCU-3'; and 5'-ACAC GGCACUCCUUGGUAU-3' was applied (Dharmacon, Lafayette, CO, USA). Gene silencing efficiency after siRNA treatment was verified by mRNA and protein analysis 24 and $72 \mathrm{~h}$ after transfection, respectively.

For plasmid transfections, HT-22 cells were seeded at a density of 60,000 cells in $900 \mu \mathrm{l} /$ well in a 24 -well plate. The medium was substituted immediately before transfection by DMEM (Invitrogen) without antibiotics and serum. A stock solution of $25 \mathrm{kD}$ polyethylenimine (PEI; kind gift from BASF, Germany) was prepared beforehand by dissolving PEI in sterile water. PEI polyplexes were generated in situ, by incubating PEI at a final concentration of $17.5 \mu \mathrm{g} / \mathrm{ml}$ and the respective plasmid at $20 \mu \mathrm{g} / \mathrm{ml}$ in a $5 \%$ glucose solution. After $20 \mathrm{~min}$ of incubation, $100 \mu \mathrm{l}$ of the polyplexes were added to $900 \mu \mathrm{l}$ HT-22 cells, followed by an incubation period of $4 \mathrm{~h}$. Afterwards the medium was replaced again by standard DMEM-medium containing serum and antibiotics. For control transfections, a plasmid encoding for mitochondrial targeting green fluorescent protein was used [22].

\section{PCR}

RNA extracts were prepared from HT-22 cells using the Nucleo Spin Kit II (Machery-Nagel, Duerren, Germany). One-step reverse transcriptase-PCR (RT-PCR) was performed using the SuperscriptIII One Step RT-PCR (Invitrogen). Specific primers were used for murine CYLD (fw: 5'-CTCAGCCTATTTAGAAACAGACT-3'; rv 5'TACACCTCTTGACATAAAGGC-3') and for murine GAPDH (fw: 5'-GTCTTCACCACCATGGAGAAGGC-3'; rv 5'-AAGGCCATGCCAGTGAGCTTCCC-3'). PCR products were separated on $1.5 \%$ agarose gel and visualized by SYBR Safe DNA gel stain (Invitrogen).

\section{Western blotting and immunoprecipitation}

Cells were lysed in standard cell lysis buffer at $\mathrm{pH} 7.8$ containing $0.25 \mathrm{M}$ D-Mannitol, $0.05 \mathrm{M}$ Tris-base, $1 \mathrm{mM}$ EDTA, 1 mM EGTA, and 1\% Triton X-100. The buffer was supplemented with a tablet complete mini protease inhibitor cocktail tablet and a phosphatase inhibitor PhosphoSTOP tablet (both from Roche, Mannheim, Germany). Protein content was determined by the Pierce BCA Kit (Thermo Fisher Scientific, Rockford, IL, USA). Immunoprecipitation was performed using DynaBeads coupled with Protein A according to the manufacturer's protocol (Invitrogen). Crosslinking of the beads was achieved by BisSulfosuccinimidyl-substrate $\left(\mathrm{BS}^{3}\right.$, Thermo Fisher Scientific). Western blot analysis was performed as previously described [54]. Briefly, the blots were probed at $4{ }^{\circ} \mathrm{C}$ overnight using the following antibodies: anti-CYLD polyclonal antibody (Santa Cruz Biotechnology, Santa Cruz, CA, USA), anti-RIP1 monoclonal antibody (BD Biosciences, Pharmingen, CA, USA), anti-RIP3 (ProSci, San Diego, CA, USA), anti-K63 ubiquiting (Millipore, \#051308) anti-cIAP (R\&D Systems, Minneapolis, MN, USA),

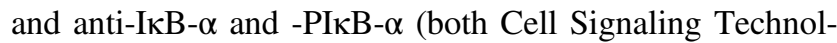
ogy, Beverly, MA, USA). Equal protein loading was controlled by probing the membrane with a monoclonal antiActin antibody (MP-Biomedicals, Solon, OH, USA). Membranes were then exposed to the appropriate horseradish peroxidase (HRP)-conjugated goat anti-rabbit or horse anti-mouse secondary antibody (1:2500, Vector Laboratories, Burlingame, CA, USA) followed by a chemiluminescence detection of antibody binding using HRPJuice (PJK GmbH, Kleinblittersdorf, Germany). Chemiluminescence was detected and quantified using a ChemiDoc XRS system running the Quantity One Software (both from Bio-Rad, Munich, Germany).

\section{Luciferase assay}

$\mathrm{NF}-\kappa \mathrm{B}$ activity was determined by dual luciferase reporter assay by co-transfecting HT-22 cells with a NF-кBluciferase reporter plasmid with firefly luciferase reporter (\#6053-1, Clontech, Heidelberg, Germany) and pRL-TK (\#E2241, Promega, Madison, WI, USA) with renila luciferase reporter as a transfection control. Luciferase activity was performed with the Dual-Luciferase Assay Kit (Promega) following the manufacturer's protocol. Luminescence was measured with FluoStar (BMG Labtechy) [55].

\section{Animals and in vivo studies}

\section{Ethics statement}

All experimental procedures were approved by the Ethical Review Board of the Government of Upper Bavaria (protocol no. 55.2.1.54-2531/118-05). The manuscript was prepared according to the ARRIVE guidelines [56]. Mice were maintained as per the guidelines of FELASA in standarad housing cages with access to food and water ad libitum [57].

\section{Randomization}

All animals were randomly assigned to the treatment or control group by drawing lots; the surgical preparation and 
neurological testing was performed by a researcher blinded to the treatment. All data were prepared and analyzed by a researcher blinded to the treatment.

\section{Controlled cortical impact}

Six-8-week-old CYLD homozygous, hetereozygous, and wild-type mice weighing 24-26g were used for the experiments. Anesthesia was induced with $4 \%$ isoflurane for $30 \mathrm{~s}$ and then continued with $1-1.5 \%$ isoflurane in $30 \%$ oxygen and $69 \% \mathrm{~N}_{2} \mathrm{O}$ delivered via face mask to spontaneously breathing animals. TBI was induced after right parietal craniotomy by controlled cortical impact (CCI) as previously described [58] using an impact depth of $1 \mathrm{~mm}$, a velocity of $8 \mathrm{~m} / \mathrm{s}$, and $150 \mathrm{~ms}$ contact time. Body temperature was continuously kept at $37^{\circ} \mathrm{C}$. After replacement of the bone flap with tissue glue and wound closure, animals were allowed to wake up and kept in a heating chamber kept at $34{ }^{\circ} \mathrm{C}$ for $1 \mathrm{~h}$ in order to avoid hypothermia. Buprenorphine $(100 \mathrm{mg} / \mathrm{kg})$ was administered i.p. t.i.d. in the first $48 \mathrm{~h}$.

\section{Measurement of intracranial pressure (ICP)}

Twenty-four hours after trauma, animals were reanesthetized. A burrhole was placed anterior to CCI craniotomy. ICP was measured via an intraparenchymal pressure sensor (ICP EXPRESS, Codman, Raynham, MA) over $5 \mathrm{~min}$.

\section{Assessment of lesion volume}

Twenty-four hours or 7 days after CCI, animals were killed in deep isoflurane anesthesia; brains were removed and immediately frozen in powdered dry ice. In all, $10 \mu \mathrm{m}$ coronal Cryo sections were prepared every $500 \mu \mathrm{m}$, stained according to Nissl, and then digitally photographed. The contusion area was measured using a standard image analysing system (analySIS 3.2 for Olympus DP-soft, soft imaging system, Muenster, Germany).

\section{Brain water content}

Brains were removed after $24 \mathrm{~h}$ and immediately cooled to $4{ }^{\circ} \mathrm{C}$. Optical bulbs and cerebellum were removed, hemispheres were separated, and the wet weight was assessed. Dry weight was obtained after keeping the hemispheres at $100{ }^{\circ} \mathrm{C}$ for $24 \mathrm{~h}$. Brain water content was calculated as the percentage of whole brain weight [58].

Acknowledgements This study was partly supported by the DFG (Cu43/6-1). SM-164 was a kind gift from Shamoeng Wang, University of Michigan, Ann Arbor, Michigan, USA. We thank Mathieu JM
Bertrand, Inflammation Research Center, VIB, Ghent University, Gent, Belgium for valuable suggestions and comments in redrafting this manuscript. We thank the excellent technical support by Mrs. Katharina Elsässer and Ms. Eileen Daube.

Author contributions GKG, NAT, and SD performed the in vitro experiments, interpreted data. NAT performed in vivo experiments and analyzed in vivo data. IE, LH, and CR performed additional immunoprecipitation and siRNA experiments and analyzed data. NP and CC conceived the concept of the study, interpreted all experiments and wrote the manuscript supported by GKG, NAT, and SD.

Conflict of Interest The authors declare that they have no conflict of interest.

Open Access This article is licensed under a Creative Commons Attribution-NonCommercial-NoDerivatives 4.0 International License, which permits any non-commercial use, sharing, distribution and reproduction in any medium or format, as long as you give appropriate credit to the original author(s) and the source, and provide a link to the Creative Commons license. You do not have permission under this license to share adapted material derived from this article or parts of it. The images or other third party material in this article are included in the article's Creative Commons license, unless indicated otherwise in a credit line to the material. If material is not included in the article's Creative Commons license and your intended use is not permitted by statutory regulation or exceeds the permitted use, you will need to obtain permission directly from the copyright holder. To view a copy of this license, visit http://creativecommons.org/licenses/by-nc-nd/4.0/.

\section{References}

1. Vanden Berghe T, Kaiser WJ, Bertrand MJ, Vandenabeele P. Molecular crosstalk between apoptosis, necroptosis, and survival signaling. Mol Cell Oncol. 2015;2:e975093.

2. Li J, McQuade T, Siemer AB, Napetschnig J, Moriwaki K, Hsiao Y-S, et al. The RIP1/RIP3 necrosome forms a functional amyloid signaling complex required for programmed necrosis. Cell. 2012;150:339-50.

3. He S, Wang L, Miao L, Wang T, Du F, Zhao L, et al. Receptor interacting protein kinase-3 determines cellular necrotic response to TNF-alpha. Cell. 2009;137:1100-11.

4. Rodriguez DA, Weinlich R, Brown S, Guy C, Fitzgerald P, Dillon $\mathrm{CP}$, et al. Characterization of RIPK3-mediated phosphorylation of the activation loop of MLKL during necroptosis. Cell Death Differ. 2016;23:76-88.

5. Vanden Berghe T, Hassannia B, Vandenabeele P. An outline of necrosome triggers. Cell Mol Life Sci. 2016;73:2137-52.

6. Kaiser WJ, Upton JW, Long AB, Livingston-Rosanoff D, DaleyBauer LP, Hakem R, et al. RIP3 mediates the embryonic lethality of caspase-8-deficient mice. Nature. 2011;471:368-72.

7. Vandenabeele P, Declercq W, van Herreweghe F, Vanden Berghe T. The role of the kinases RIP1 and RIP3 in TNF-induced necrosis. Sci Signal. 2010;3:re4.

8. Degterev A, Hitomi J, Germscheid M, Ch'en IL, Korkina O, Teng $\mathrm{X}$, et al. Identification of RIP1 kinase as a specific cellular target of necrostatins. Nat Chem Biol. 2008;4:313-21.

9. Vandenabeele P, Galluzzi L, Vanden Berghe T, Kroemer G. Molecular mechanisms of necroptosis: an ordered cellular explosion. Nat Rev Mol Cell Biol. 2010;11:700-14.

10. Kalai M, van Loo G, Vanden Berghe T, Meeus A, Burm W, Saelens $X$, et al. Tipping the balance between necrosis and apoptosis in human and murine cells treated with interferon and dsRNA. Cell Death Differ. 2002;9:981-94. 
11. Bignell GR, Warren W, Seal S, Takahashi M, Rapley E, Barfoot $\mathrm{R}$, et al. Identification of the familial cylindromatosis tumoursuppressor gene. Nat Genet. 2000;25:160-5.

12. Courtois G, Gilmore TD. Mutations in the NF-kappaB signaling pathway: implications for human disease. Oncogene. 2006;25:6831-43.

13. Kovalenko A, Chable-Bessia C, Cantarella G, Israël A, Wallach $\mathrm{D}$, Courtois $\mathrm{G}$. The tumour suppressor CYLD negatively regulates NF-kappaB signalling by deubiquitination. Nature. 2003; 424:801-5.

14. Hitomi J, Christofferson DE, Ng A, Yao J, Degterev A, Xavier RJ, et al. Identification of a molecular signaling network that regulates a cellular necrotic cell death pathway. Cell. 2008;135:1311-23.

15. Bertrand MJM, Milutinovic S, Dickson KM, Ho WC, Boudreault A, Durkin J, et al. cIAP1 and cIAP2 facilitate cancer cell survival by functioning as E3 ligases that promote RIP1 ubiquitination. Mol Cell. 2008;30:689-700.

16. Vanlangenakker N, Vanden Berghe T, Bogaert P, Laukens B, Zobel K, Deshayes K, et al. cIAP1 and TAK1 protect cells from TNF-induced necrosis by preventing RIP1/RIP3-dependent reactive oxygen species production. Cell Death Differ. 2011; 18:656-65.

17. Wang L, Du F, Wang X. TNF-alpha induces two distinct caspase8 activation pathways. Cell. 2008;133:693-703.

18. O’Donnell MA, Perez-Jimenez E, Oberst A, Ng A, Massoumi R, Xavier R, et al. Caspase 8 inhibits programmed necrosis by processing CYLD. Nat Cell Biol. 2011;13:1437-42.

19. Murphy TH, Miyamoto M, Sastre A, Schnaar RL, Coyle JT. Glutamate toxicity in a neuronal cell line involves inhibition of cystine transport leading to oxidative stress. Neuron. 1989;2:1547-58.

20. Tobaben S, Grohm J, Seiler A, Conrad M, Plesnila N, Culmsee C. Bid-mediated mitochondrial damage is a key mechanism in glutamate-induced oxidative stress and AIF-dependent cell death in immortalized HT-22 hippocampal neurons. Cell Death Differ. 2011;18:282-92.

21. Culmsee C, Zhu C, Landshamer S, Becattini B, Wagner E, Pellecchia $\mathrm{M}$, et al. Apoptosis-inducing factor triggered by poly (ADP-ribose) polymerase and Bid mediates neuronal cell death after oxygen-glucose deprivation and focal cerebral ischemia. J Neurosci. 2005;25:10262-72.

22. Landshamer S, Hoehn M, Barth N, Duvezin-Caubet S, Schwake $\mathrm{G}$, Tobaben S, et al. Bid-induced release of AIF from mitochondria causes immediate neuronal cell death. Cell Death Differ. 2008; 15:1553-63.

23. Plesnila N, Zhu C, Culmsee C, Gröger M, Moskowitz MA, Blomgren K. Nuclear translocation of apoptosis-inducing factor after focal cerebral ischemia. J Cereb Blood Flow Metab. 2004;24:458-66.

24. Guerriero RM, Giza CC, Rotenberg A. Glutamate and GABA imbalance following traumatic brain injury. Curr Neurol Neurosci Rep. 2015;15:27.

25. Mattson MP, Meffert MK. Roles for NF-kappaB in nerve cell survival, plasticity, and disease. Cell Death Differ. 2006;13:852-60.

26. Schwaninger M, Inta I, Herrmann O. NF-kappaB signalling in cerebral ischaemia. Biochem Soc Trans. 2006;34:1291-4.

27. Byun JY, Yune TY, Lee JY, Yeo SG, Park MS. Expression of CYLD and NF-kappaB in human cholesteatoma epithelium. Mediat Inflamm. 2010;2010:796315.

28. Sun S-C. CYLD: a tumor suppressor deubiquitinase regulating NF-kappaB activation and diverse biological processes. Cell Death Differ. 2010;17:25-34.

29. Schweighöfer H, Rummel C, Roth J, Rosengarten B. Modulatory effects of vagal stimulation on neurophysiological parameters and the cellular immune response in the rat brain during systemic inflammation. Intensive Care Med Exp. 2016; $4: 19$.

30. Sun L, Wang H, Wang Z, He S, Chen S, Liao D, et al. Mixed lineage kinase domain-like protein mediates necrosis signaling downstream of RIP3 kinase. Cell. 2012;148:213-27.

31. Wright A, Reiley WW, Chang M, Jin W, Lee AJ, Zhang M, et al. Regulation of early wave of germ cell apoptosis and spermatogenesis by deubiquitinating enzyme CYLD. Dev Cell. 2007;13:705-16.

32. Fearns C, Pan Q, Mathison JC, Chuang T-H. Triad3A regulates ubiquitination and proteasomal degradation of RIP1 following disruption of Hsp90 binding. J Biol Chem. 2006;281: 34592-600.

33. Moquin D, Chan FK-M. The molecular regulation of programmed necrotic cell injury. Trends Biochem Sci. 2010;35:434-41.

34. Schenk B, Fulda S. Reactive oxygen species regulate Smac mimetic/TNF $\alpha$-induced necroptotic signaling and cell death. Oncogene. 2015;34:5796-806.

35. Zhang Y, Su SS, Zhao S, Yang Z, Zhong C-Q, Chen X, et al. RIP1 autophosphorylation is promoted by mitochondrial ROS and is essential for RIP3 recruitment into necrosome. Nat Commun. 2017;8:14329.

36. Slemmer JE, Zhu C, Landshamer S, Trabold R, Grohm J, Ardeshiri A, et al. Causal role of apoptosis-inducing factor for neuronal cell death following traumatic brain injury. Am J Pathol. 2008;173:1795-805.

37. Moquin DM, McQuade T, Chan FK-M. CYLD deubiquitinates RIP1 in the TNF $\alpha$-induced necrosome to facilitate kinase activation and programmed necrosis. PLoS ONE. 2013;8:e76841.

38. Davis CW, Hawkins BJ, Ramasamy S, Irrinki KM, Cameron BA, Islam K, et al. Nitration of the mitochondrial complex I subunit NDUFB8 elicits RIP1- and RIP3-mediated necrosis. Free Radic Biol Med. 2010;48:306-17.

39. Neitemeier S, Jelinek A, Laino V, Hoffmann L, Eisenbach I, Eying R, et al. BID links ferroptosis to mitochondrial cell death pathways. Redox Biol. 2017;12:558-70.

40. Seiler A, Schneider M, Förster H, Roth S, Wirth EK, Culmsee C, et al. Glutathione peroxidase 4 senses and translates oxidative stress into 12/15-lipoxygenase dependent- and AIF-mediated cell death. Cell Metab. 2008;8:237-48.

41. Hentze H, Schmitz I, Latta M, Krueger A, Krammer PH, Wendel A. Glutathione dependence of caspase- 8 activation at the death-inducing signaling complex. J Biol Chem. 2002; 277:5588-95.

42. Mattson MP, Culmsee C, Yu Z, Camandola S. Roles of nuclear factor kappaB in neuronal survival and plasticity. J Neurochem. 2000;74:443-56.

43. Dondelinger $\mathrm{Y}$, Jouan-Lanhouet $\mathrm{S}$, Divert $\mathrm{T}$, Theatre $\mathrm{E}$, Bertin J, Gough PJ, et al. NF-KB-independent role of IKK $\alpha / \mathrm{IKK} \beta$ in preventing RIPK1 kinase-dependent apoptotic and necroptotic cell death during TNF signaling. Mol Cell. 2015;60:63-76.

44. Ting AT, Bertrand MJM. More to life than NF- $\kappa B$ in TNFR1 signaling. Trends Immunol. 2016;37:535-45.

45. Varfolomeev E, Goncharov T, Fedorova AV, Dynek JN, Zobel K, Deshayes K, et al. c-IAP1 and c-IAP2 are critical mediators of tumor necrosis factor alpha (TNFalpha)-induced NF-kappaB activation. J Biol Chem. 2008;283:24295-9.

46. Northington FJ, Chavez-Valdez R, Graham EM, Razdan S, Gauda EB, Martin LJ. Necrostatin decreases oxidative damage, inflammation, and injury after neonatal HI. J Cereb Blood Flow Metab. 2011;31:178-89.

47. Degterev A, Huang Z, Boyce M, Li Y, Jagtap P, Mizushima N, et al. Chemical inhibitor of nonapoptotic cell death with therapeutic potential for ischemic brain injury. Nat Chem Biol. 2005;1:112-9. 
48. Zhang H-B, Cheng S-X, Tu Y, Zhang S, Hou S-K, Yang Z. Protective effect of mild-induced hypothermia against moderate traumatic brain injury in rats involved in necroptotic and apoptotic pathways. Brain Inj. 2017;31:406-15.

49. Liu T, Zhao D-x, Cui H, Chen L, Bao Y-h, Wang Y, et al. Therapeutic hypothermia attenuates tissue damage and cytokine expression after traumatic brain injury by inhibiting necroptosis in the rat. Sci Rep. 2016;6:24547.

50. Wang Y-Q, Wang L, Zhang M-Y, Wang T, Bao H-J, Liu W-L, et al. Necrostatin-1 suppresses autophagy and apoptosis in mice traumatic brain injury model. Neurochem Res. 2012; 37:1849-58.

51. You Z, Savitz SI, Yang J, Degterev A, Yuan J, Cuny GD, et al. Necrostatin-1 reduces histopathology and improves functional outcome after controlled cortical impact in mice. J Cereb Blood Flow Metab. 2008;28:1564-73.

52. Takahashi N, Duprez L, Grootjans S, Cauwels A, Nerinckx W, DuHadaway JB, et al. Necrostatin-1 analogues: critical issues on the specificity, activity and in vivo use in experimental disease models. Cell Death Dis. 2012;3:e437.
53. Diemert S, Dolga AM, Tobaben S, Grohm J, Pfeifer S, Oexler E, et al. Impedance measurement for real time detection of neuronal cell death. J Neurosci Methods. 2012;203:69-77.

54. Ganjam GK, Benzler J, Pinkenburg O, Boucsein A, Stöhr S, Steger J, et al. Overexpression of suppressor of cytokine signaling 3 in the arcuate nucleus of juvenile Phodopus sungorus alters seasonal body weight changes. J Comp Physiol B. 2013; 183:1101-11.

55. Neitemeier S, Ganjam GK, Diemert S, Culmsee C. Pifithrin- $\alpha$ provides neuroprotective effects at the level of mitochondria independently of p53 inhibition. Apoptosis. 2014;19:1665-77.

56. Kilkenny C, Browne WJ, Cuthill IC, Emerson M, Altman DG. Improving bioscience research reporting: the ARRIVE guidelines for reporting animal research. J Pharmacol Pharmacother. 2010;1:94-9.

57. Guillen J. FELASA guidelines and recommendations. J Am Assoc Lab Anim Sci. 2012;51:311-21.

58. Terpolilli NA, Kim S-W, Thal SC, Kuebler WM, Plesnila N. Inhaled nitric oxide reduces secondary brain damage after traumatic brain injury in mice. J Cereb Blood Flow Metab. 2013;33:311-8. 